\title{
O comércio exterior de Cuba no século XXI e a diversificação de parcerias
}

\author{
Marcos Antonio da Silva ${ }^{1}$ \\ Guillermo A. Johnson²
}

\section{RESUMO}

O presente trabalho analisa a reinserção econômica de Cuba na primeira década do século XXI. Para tanto, procura demonstrar que o comércio exterior do país, alicerçado nos objetivos gerais da política externa cubana, indica diversificação de parcerias, superando a concentração que existiu ao longo do século XX, e tem contribuído para a recuperação econômica e maior autonomia do país.

Palavras-Chave: Cuba; Diversificação; Parcerias.

A Revolução Cubana chegou ao final do século XX marcada por um duplo desafio, herança do desmoronamento do bloco soviético com quem o país mantinha relações intensas. No âmbito interno, uma profunda crise econômica e social assolou o país, atingindo parcialmente as conquistas sociais revolucionárias (ALMENDRA, 1998; CEPAL, 2000; LÓPEZ-SEGRERA, 1995). No âmbito externo, o país viu o aprofundamento do embargo americano e a necessidade de reconstruir laços políticos e econômicos com a comunidade internacional. Este trabalho procura analisar o processo de reinserção internacional e diversificação de parcerias que têm orientado a política externa cubana neste novo século, contribuindo para a recuperação econômica e a superação do relativo isolamento.

Na primeira década do século XXI, Cuba tem desenvolvido uma política externa que, embora, mantendo as características fundamentais de décadas anteriores, procurou adaptar-se ao novo contexto. Neste sentido, dentre os aspectos tradicionais, pode-se apontar o intenso ativismo, pelo globalismo, pela afirmação da soberania nacional, pela

\footnotetext{
${ }^{1}$ Professor de Ciência Política do curso de Ciências Sociais da Universidade Federal do Rio Grande do Norte (UFRN). Membro do LIAL (Laboratório Interdisciplinar de Estudos sobre América Latina).

2 Professor de Ciência Política do curso de Ciências Sociais da Universidade Federal da Grande Dourados (UFGD). Coordenador do LIAL (Laboratório Interdisciplinar de Estudos sobre América Latina).
} 
inserção crítica no sistema internacional, pela relação intensa com América Latina e pela cooperação internacional fundada no internacionalismo, entre outras (PISANI, 2002; SALAZAR, 1997; AYERBE, 2011; ALZUGARAY TRETO, 2003). A estas características podese acrescentar que, a partir dos anos 90, a política externa cubana, adaptando a conjuntura interna e a internacional, incorporou o pragmatismo, o papel propositivo e negociador nos conflitos regionais (América Central e do Sul), a cooperação internacional fundada na diplomacia social e, principalmente, a diversificação de parcerias políticas e econômicas. (DOMINGUEZ, 2003; SALAZAR, 2000; ALZUGARAY TRETO, 2003; SANCHEZPARODI, 1998; SERBIN, 2011)³.

Sendo assim, tem início um período de "atualização" do sistema, tendo, como pano de fundo, as demandas sociais e econômicas, e a necessidade de recomposição das relações internas. Embora reconhecendo que tal estratégia de diversificação de parceiros possui diversas dimensões (política, diplomática, ideológica etc.) que fogem ao escopo deste trabalho, pudemos percebê-la e analisá-la no âmbito das relações econômicas, considerando o intercâmbio comercial.

O desempenho do comércio exterior e a diversificação de parcerias econômicas podem ser observados no seguinte quadro:

Quadro 1- Comércio Exterior

Intercâmbio de mercadorias (continentes e países).

\begin{tabular}{|l|l|l|l|l|l|}
\hline PAÍ́SES & 2000 & 2001 & 2002 & 2003 & 2004 \\
\hline Total & $\mathbf{6 4 7 0 8 7 2}$ & $\mathbf{6 4 1 5} 126$ & $\mathbf{5 6 0 9 8 1 8}$ & $\mathbf{6 3 6 0 7 8 0}$ & $\mathbf{7 9 4 7 3 1 6}$ \\
\hline EUROPA & $\mathbf{2 8 0 9 7 4 2}$ & $\mathbf{2 7 5 6 5 9 2}$ & $\mathbf{2 3 2 9 0 1 4}$ & $\mathbf{2 5 0 0 4 7 3}$ & $\mathbf{2 7 0 9 4 2 5}$ \\
\hline Alemanha & 198723 & 119486 & 96955 & 140633 & 154190 \\
\hline Espanha & 893338 & 837303 & 724920 & 773443 & 819138 \\
\hline Rússia & 435877 & 486420 & 352899 & 191168 & 195558 \\
\hline
\end{tabular}

\footnotetext{
${ }^{3}$ Um elemento que aprofundou o pragmatismo e a reorientação de tal política relaciona-se a substituição da liderança de Fidel Castro por Raul Castro, que como apontam Alzugaray Treto (2007) e Serbin (2011). Este chega a afirmar que: "Este nuevo factor se articula con um creciente pragmatismo de la política exterior cubana, particularmente a partir del reemplazo de Fidel por Raúl Castro en el gobierno, que se caracteriza por renovar y adoptar nuevos compromisos internacionales en el marco de una estrategia de diversificación de las relaciones externas de la isla para asegurar mejor la supervivencia econômica del país, sin poner en riesgo el modelo político existente" (Serbin: 2011, p. 233).
} 


\begin{tabular}{|c|c|c|c|c|c|}
\hline França & 332287 & 331626 & 262448 & 224695 & 187343 \\
\hline Holanda & 202502 & 400861 & 360888 & 485789 & 695960 \\
\hline Itália & 330800 & 308316 & 294648 & 347567 & 285391 \\
\hline ÁSIA & 988489 & 1034959 & 997086 & 1073636 & 1251185 \\
\hline China & 524301 & 622231 & 592852 & 583501 & 670439 \\
\hline Japão & 111102 & 110283 & 95970 & 127803 & 185797 \\
\hline Vietnam & 48957 & 59432 & 69204 & 80805 & 146946 \\
\hline Outros & 153240 & 119261 & 83400 & 109334 & 113494 \\
\hline AFRICA & 37492 & 36002 & 35950 & 102974 & 77539 \\
\hline Argélia & 820 & 1305 & 9015 & 78077 & 66807 \\
\hline AMÉRICA & 2630128 & 2525780 & 2186765 & 2632961 & 3852516 \\
\hline Argentina & 77184 & 80517 & 40752 & 44592 & 117808 \\
\hline Brasil & 151390 & 164578 & 117558 & 128026 & 223318 \\
\hline Canadá & 589019 & 592388 & 455131 & 506940 & 754986 \\
\hline EUA & 0 & 4414 & 173615 & 327252 & 443900 \\
\hline Venezuela & 912409 & 9734123 & 744748 & 875714 & 1509776 \\
\hline México & 337815 & 315955 & 229352 & 236293 & 266213 \\
\hline
\end{tabular}

\section{Comércio Exterior}

\section{Intercâmbio de mercadorias (continuação do quadro 1).}

\begin{tabular}{|l|l|l|l|l|l|l|l|}
\hline PAÍ́SES & 2005 & 2006 & 2007 & 2008 & 2009 & 2010 & 2011 \\
\hline Total & $\mathbf{9 7 6 3 7 0 2}$ & $\mathbf{1 2 4 2 2 ~ 4 4 8}$ & $\mathbf{1 3 7 6 4 8 7 5}$ & $\mathbf{1 7 8 9 8 2 5 1}$ & $\mathbf{1 1 ~ 7 6 9 0 1 4}$ & $\mathbf{1 5 2 4 4 5 4 2}$ & $\mathbf{1 9 9 9 7 0 0 0}$ \\
\hline EUROPA & $\mathbf{2 8 6 8 1 6 9}$ & $\mathbf{3 8 7 8 3 9 8}$ & $\mathbf{3 5 5 7 8 7 4}$ & $\mathbf{3 9 7 8 . 2 1 0}$ & $\mathbf{2 7 5 9 3 0 8}$ & $\mathbf{3 ~ 0 2 0 ~ 7 7 1}$ & $\mathbf{4 0 6 1 4 9 6}$ \\
\hline Alemanha & 329505 & 639876 & 395989 & 404658 & 308981 & 296538 & 56309 \\
\hline Espanha & 828459 & 1016533 & 1154838 & 1427275 & 906336 & 946907 & 1185077 \\
\hline Rússia & 189815 & 288772 & 362358 & 324706 & 283129 & 284814 & 292558 \\
\hline França & 217459 & 249742 & 235120 & 272634 & 185886 & 297900 & 367496 \\
\hline Holanda & 647139 & 855977 & 526599 & 386208 & 306104 & 420614 & 729378 \\
\hline
\end{tabular}




\begin{tabular}{|c|c|c|c|c|c|c|c|}
\hline Itália & 304105 & 434481 & 415196 & 552023 & 353263 & 331187 & 439553 \\
\hline ÁSIA & 1771572 & 2715691 & 3566082 & 3760439 & 2491965 & 2787735 & 3060780 \\
\hline China & 996289 & 1815101 & 2446404 & 2157898 & 1687508 & 1900707 & 2067942 \\
\hline Coréia do Sul & 84544 & 183047 & 333591 & 433012 & 113022 & 99017 & 130819 \\
\hline Japão & 259829 & 183254 & 236895 & 162593 & 94201 & 86347 & 88344 \\
\hline Vietnam & 252329 & 192243 & 283949 & 516566 & 279179 & 268939 & 313743 \\
\hline Outros & 80970 & 113821 & 109067 & 161480 & 108916 & 68220 & 210793 \\
\hline AFRICA & 166720 & 246257 & 300702 & 578513 & 421022 & 409737 & 625184 \\
\hline Argélia & 143391 & 229839 & 234349 & 248131 & 170613 & 214139 & 320112 \\
\hline AMÉRICA & 4885194 & 5515126 & 6250292 & 9450137 & 6083009 & 8976926 & 12171671 \\
\hline Argentina & 160884 & 115668 & 150407 & 140021 & 144804 & 146835 & 167532 \\
\hline Brasil & 352202 & 453011 & 446380 & 641820 & 570964 & 501409 & 725182 \\
\hline Canadá & 777796 & 896985 & 1399689 & 1412400 & 741328 & 971820 & 1198057 \\
\hline EUA & 476311 & 483591 & 581657 & 962767 & 598212 & 410756 & 431009 \\
\hline Venezuela & 2265191 & 2641210 & 2693639 & 4887004 & 3135490 & 6027679 & 8334486 \\
\hline México & 289517 & 274361 & 219678 & 383304 & 337280 & 380558 & 477650 \\
\hline
\end{tabular}

Fonte: ONE, Anuário Estadístico de Cuba, 2011.

0 primeiro aspecto a destacar refere-se ao aumento do volume total, indicando que a lenta e tortuosa recuperação econômica dos anos 90 identificada pela CEPAL (2000) foi superada por uma recuperação crescente e contínua na década de 2000. Neste sentido, o intercâmbio comercial cubano triplicou, aumentando de U\$ 6,5 milhões para cerca de U\$ 20 milhões. Tal dado é revelador da recuperação econômica do país, porém, deve-se levar em consideração a necessidade de analisar o perfil das importações e exportações para que se compreenda sua natureza, desenvolvimento e tendências4.

\footnotetext{
4 Neste sentido, como aponta Mesa-Lago (2009), as importações cubanas referiam-se a alimentos da cesta básica, a produtos manufaturados e a combustíveis, mesmo considerando o preço preferencial fornecido do petróleo venezuelano. Em relação às exportações, observa-se uma maior diversificação e uma mudança substancial que começa nos anos 90 e se estende a esta primeira década do século XXI, com a superação, não intencional, da dependência do açúcar e a manutenção de um padrão concentrado em produtos primários (níquel, tabaco, frutas e pescado), cimento, da indústria farmacêutica e nos serviços.
} 
0 segundo aspecto relevante, que orienta esta análise, refere-se à evidente diversificação de parcerias e à política de relações econômicas globais, aspecto inédito na história do país, considerando os laços anteriores com EUA (pré-59) e URSS (pós-59) que concentraram mais de 65\% do comércio exterior do país (AYERBE, 2011; MESA-LAGO, 2009; ALMENDRA, 1998).

Neste sentido, podemos observar que, no que tange aos continentes, tais relações fundamentam-se em uma perspectiva global, sendo que o maior intercâmbio é realizado com a América (mais de 50\% em 2010 e cerca de 60\% em 2011), seguida de Europa (cerca de 30\% em 2010 e 25\% em 2011) e Ásia (em torno de 15\% nos dois anos); somente as relações com a África são pequenas no balanço geral e insignificantes com a Oceania; isto se deve ao perfil do comércio exterior cubano, bem como, no caso africano, apesar dos laços históricos e políticos com alguns países da região, as trocas comerciais sofrem o problema da similaridade e não da complementação; em relação à Oceania, as distâncias física e política e os custos parecem serem determinantes para a insignificância da relação comercial.

Na América, a relação com a Venezuela, nos marcos da ALBA e do intercâmbio baseado na troca petróleo-serviços assume dimensão importante (cerca de $40 \%$ do volume total em 2010 e 2011), mas longe da concentração existente em outros momentos. Tal parceria é reforçada pela convergência no plano geopolítico, ideológico e diplomático, que escapam ao escopo deste trabalho, indicando, no entanto, dependência da permanência de Chávez (ou chavistas) no poder. Além disto, deve-se destacar também a participação significativa do Canadá, o aumento constante do intercâmbio comercial com Brasil e México, revelando o estabelecimento de laços comerciais com Estados que tem certa ascendência econômica e política na região e procuram desempenhar papel relevante na política internacional.

Em relação à Europa, deve-se destacar o incremento das relações comerciais com a Espanha, Holanda, Itália, França e Rússia. Novamente diversificada, parte destas relações pode ser explicada pelos laços históricos e culturais (Espanha e Rússia), embora a variação indique a existência de tensões que podem afetar o intercâmbio comercial, dependendo da relação política entre os governos, o que também afeta a 
relação com os demais. Nos outros casos, deve-se considerar o perfil das importações e exportações de ambos os lados para compreender sua amplitude.

Por fim, no que se refere à Ásia, o incremento das relações comerciais com a China é evidente, confirmando a diversificação das parcerias e sua relevância, diante do papel desempenhado por este país no comércio internacional contemporâneo. Também neste caso, tal relação na esfera econômica é impulsionada pela convergência de interesses em outras esferas 5 . A China tornou-se o segundo parceiro comercial de Cuba, sendo que esta fornece açúcar e níquel (principalmente), enquanto adquire produtos manufaturados, equipamentos de transporte, além de turismo e investimentos em extração de níquel e petróleo, bem como no desenvolvimento de biotecnologia. Apesar disto, deve-se levar em consideração os interesses globais chineses e os custos da relação comercial Cuba-China, porém, as perspectivas parecem indicar um aprofundamento desta parceria. Também se destaca o fortalecimento do intercâmbio comercial com Vietnam e a Coréia do Sul.

Desta forma, analisando o quadro comercial desta primeira década, podemos constatar que China, Venezuela, União Européia e Canadá, fundamentalmente, contribuíram para a recuperação econômica do país e sua estratégia de diversificação de parceiros. Além destes, devem-se considerar as potências emergentes como Rússia, México e Brasil, como parceiros importantes. Somente uma análise mais ampla que considere outros fatores econômicos (como investimentos, cooperação, dívida etc.) e políticos poderá captar as potencialidades e os limites de tais relações. Além disto, aguardamos a publicação Anuário Estatístico de Cuba com os dados referentes a 2012, para verificarmos a continuidade (ou não) destas tendências.

\footnotetext{
${ }^{5}$ Como aponta Serbin: "En este marco, las relaciones bilaterales entre ambos países, como apunta Malamud, se apoyan en tres ejes fundamentales —el político, el económico y el estratégico. Cuba obtiene partido del apoyo político y económico chino, mientras que China se beneficia de la inteligencia sobre los Estados Unidos que obtiene del gobierno cubano. En este sentido, China tiene en Cuba un buen punto de observación (quizás el único en la región) para vigilar a los EE.UU. Por otra parte, China apoya, a través de diferentes mecanismos de cooperación, la educación, la explotación petrolera, la minería del níquel, el desarrollo tecnológico y la infraestructura de transporte cubano. En este marco, la relación es compleja en función de la combinación de los tres factores, pero mucho más intensa que com otros países de la región, en función de una estrategia regional de China que, sin embargo, tiene objetivos mucho más amplios" (Serbin, 2011, p. 229).
} 


\section{Referências Bibliográficas}

ALMENDRA, C. C. A situação econômica cubana diante da queda do Leste Europeu. In: COGGIOLA, O. Revolução Cubana: história e problemas atuais. São Paulo, Ed. Xamã, 1998.

ALZUGARAY TRETO, C. La política exterior de Cuba en la década de 90: intereses, objetivos y resultados. Política Internacional, La Habana, vol. I, n. 1, p. 14-32, enero-julio 2003.

ALZUGARAY TRET0, C. Reflexões sobre o presente e o futuro político de Cuba nos albores do século XXI- uma abordagem a partir da ilha. In: Relações Internacionais, IPRI, Lisboa, março de 2007, pgs. 89-104.

AYERBE, L. F. (org.). Cuba, Estados Unidos y América Latina frente a los desafios hemisféricos. Barcelona/Buenos Aires: Icaria/CRIES, 2011.

CEPAL. La economia cubana. Ciudad de México: Fondo de Cultura Económica, 2000.

DOMíNGUEZ, J. I. La política exterior de Cuba y el sistema internacional. In: TULCHIN, Joseph; ESPACH, Ralph. América Latina en el nuevo sistema internacional Barcelona: Bellaterra, 2004, p. 255-286.

LÓPEZ SEGRERA, Francisco. Cuba cairá? Petrópolis: Vozes, 1995.

MESA-LAGO, C. Balance económico-social de 50 años de Revolución en Cuba. In: América Latina Hoy, Salamanca, n.52, pp. 41-61, 2009.

ONE (Oficina Nacional de Estadística). Anuário Estadístico de Cuba. Havana: ONE, 2011.

PISANI, M. E. Política exterior de la revolución cubana. La Habana: Ciencias Sociales, 2002.

SÁNCHEZ-PARODI, R. Raízes e atuação da política externa cubana. In: Política Externa, São Paulo, vol. 7, n. 2, p. 153-167, 1998.

SALAZAR, L. S. El siglo XXI: posibilidades y desafíos para la revolución cubana. La Habana: Ciencias Sociales, 2000. 
SALAZAR, L. S. Cuba: ¿aislamiento o reinserción en un mundo cambiado? La Habana: Ciencias Sociales, 1997.

SERBIN, A. "Círculos concéntricos: la política exterior de Cuba en un mundo multipolar y el proceso de “actualización"”’. In: AYERBE, L. F. (org.). Cuba, Estados Unidos y América Latina frente a los desafios hemisféricos. Barcelona/Buenos Aires: Icaria/CRIES, 2011. 